\title{
Carcinoid Tumors: from the Past into the Future
}

Tariq HAMEEDa, Awadh KUMAR ${ }^{\mathrm{b}}$, Chandra Bhushan SINGHc

aDepartment of Surgery, Maulana Azad Medical College and Lok Nayak Hospital, New Delhi, India

bDepartment of Surgery, Darbhanga Medical College and Hospital, Darbhanga, India

'Department of Surgery, Maulana Azad Medical College and Lok Nayak Hospital, New Delhi, India

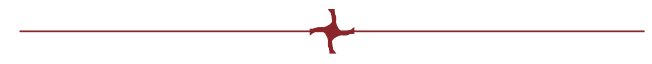

\begin{abstract}
Carcinoids are a rare and slow growing tumor, having a propensity to affect all organs but most commonly involve the gastrointestinal tract, followed by lungs. Carcinoid tumors secrete a variety of peptides and neuroamines. Though clinical presentation is varied and depends on the involved organ along with produced neuroactive amines, common symptoms include flushing, explosive watery diarrhoea and bronchospasm.

Estimation of 5-HIAA in 24-hour urine is highly specific. Serum chromogranin is highly sensitive even in non-secretory carcinoids. Octreoscan along with MIBG is a better diagnostic modality as compared to computed tomography or magnetic resonance imaging alone.

Treatment involves a multidisciplinary approach, including resection of primary tumor and debulking, embolisation of liver carcinoids, somatostatin analogues and chemotherapy. Molecular target therapy with Sunitinib and Bevacizumab have been shown to have a promising role in treatment, with higher response rate and slower progression.
\end{abstract}

Keywords: carcinoid tumors, neuroendocrine tumors, molecular target therapy.

\footnotetext{
Address for correspondence:

Dr. Tariq Hameed, Assistant Professor

Department of Surgery, Maulana Azad Medical College, New Delhi, India

Email: drtariqhameed@gmail.com
}

\section{INTRODUCTION}

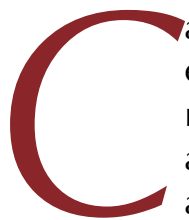

arcinoid tumors, a subset of neuroendocrine tumors, are very uncommon slow growing tumors (1). They arise from enterochromaffin cells and secrete a variety of peptides and neuroamines. 5-HT containing cells are stained with chromium or chrome salts, so are labelled as enterchromaffin. As enterochromaffin cells (Kulchitsky cells) are present in crypts of Lieberkühn of the gut, carcinoid tumors are most common in the gastrointestinal tract (GIT), including the stomach, small intestine, appendix, colon and rectum. Approximately $25 \%$ of carcinoid tumors are found in the lungs, where they 
comprise less than $1 \%$ of all primary lung cancers (2). However, almost any organ of the body can be affected, including the ovary, cervix, uterus, testis, thymus, head and neck and breasts (3). Theodor Langhans first described the histology of carcinoid tumors in 1867 and Otto Lubarsch presented a report of two patients with ileal carcinoid tumors which was discovered on autopsy (1).

\section{CLINICAL PRESENTATION}

linical presentation depends on location, aggressiveness, production of biologically active amines and peptides, paraneoplastic syndromes and tendency for metastasis. Vasodilatory effects of biologically active amines, peptides and prostaglandins cause flushing, wheezing (bronchospasm), gastrointestinal symptoms such as diarrhoea, abdominal pain, dyspepsia, and malabsorption, Pellagra (as tryptophan is diverted from the synthesis of niacin to that of serotonin), cardiac symptoms (right-sided valvular disease, mostly tricuspid regurgitation), fatigue, and sometimes cognitive impairment (4).

Of all symptoms, flushing is the most common presentation and is seen in more than $80 \%$ of patients. It is paroxysmal, upper body such as the face, neck, and upper trunk ranges from salmon pink to dark red in pigmentation, and it can stay from 30 seconds to 30 minutes. Flushing occurs spontaneously but can also be precipitated by eating, stress, liver palpation, anaesthesia or alcohol (5).

About $80 \%$ of patients have explosive, bloodless and watery diarrhoea. Diarrhoea persists even on fasting. It may be associated with abdominal cramps and frequency may be as high as 30 times a day (5). A misdiagnosis of irritable bowel syndrome (IBS) is very common in midgut carcinoids (6).

Cardiac involvement is seen in $60-70 \%$ of patients, usually involving the right-sided heart valves and eventually leading to right heart failure. Usually, only carcinoid tumours that invade the liver result in pathological changes to the heart, because vasoactive products are deactivated in the liver. Paraneoplastic syndrome with release of 5-hydroxytryptamine (5-HT or serotonin), histamine, tachykinins, transforming growth factor- $\beta$ (TCF- $\beta$ ) and prostaglandins leads to clinical manifestations. Characteristic findings include fibrous plaques over tricuspid valve, pulmonary valve, cardiac chambers, venae cavae, pulmonary artery, and coronary sinus. This fibrous tissue leads to distortion of normal anatomy of valves, resulting in stenosis and regurgitation (7). As these hormonal substances are metabolised and deactivated in lungs, valves of left side are comparatively spared.

Bronchospasm is uncommonly seen in only $<20 \%$ of patients. It presents as wheezing and difficulty in breathing.

\section{EVALUATION}

C iagnosis of carcinoid tumors is often delayed as patients are asymptomatic and present with multiple non-specific symptoms.

\section{Biochemical assessment}

Estimation of 5-hydroxyindoleacetic acid (5-HIAA) in a 24-hour urine sample has been found to be highly specific (100\%) for the diagnosis of carcinoid disease but has a low sensitivity $(73 \%)(8,9)$. Sensitivity is low because there are carcinoids which do not secrete serotonin. Serotonin may be falsely raised in celiac sprue, Whipple's disease, and SBO (10).

Chromogranin A is a non-specific glycoprotein secreted by neuroendocrine tumors. It has a high sensitivity. It is good for both screening and follow up. Serum chromogranin is a better test for non-secretory and atypical carcinoids (1). False positive results are seen in chronic kidney/liver failure, inflammatory bowel diseases, atrophic gastritis or prolonged use of proton pump inhibitors (11).

\section{Diagnostic imaging}

Once the diagnosis of carcinoid tumors is confirmed on biochemical tests, a multimodal approach is used for tumor localisation. Computed tomography (CT) is the most commonly employed diagnostic tool for tumor identification, localisation and metastasis (1). Abdominal CT (with triphasic CT of the liver) is the diagnostic test of choice. Magnetic resonance imaging (MRI) with hepatocyte-specific contrast agent has a greater sensitivity for liver and mesentery metastasis (12).

Carcinoid tumors of small intestine and colon may be detected by barium studies as submuco- 
sal filling defects or polypoidal or ulcerated masses (13).

\section{Nuclear medicine}

The use of radiolabeled receptor-binding peptides has a considerable advantage in terms of diagnostic and therapeutic information. Indium-111 tagged Octreotide is used for the localisation of primary tumor (1). Octreoscan has more than 90\% sensitivity in symptomatic patients and it is superior to cross sectional imaging with CT or MRI $(1,5)$. Octreoscan is useful in predicting tumor response to somatostatin receptor analogue therapy.

Metaiodobenzylguanidine (MIBG) is a norepinephrine analogue which is also used to localise carcinoid tumors. These scans are positive in $60-70 \%$ of patients (8). Sensitivity reaches up to 95\% if Octreoscan and MIBG are used together (14).

Carcinoid tumors have a low proliferative activity and because of this, FDG-PET is not a very useful investigative modality. Advances in PET tracer development are very encouraging. The use of 11-C-5-hydroxytryptophan (11-C-5-HTP) and 18-F-dihydroxy-phenyl-alanine (18F-DOPA) has resulted in improved detection and localisation of carcinoid tumors. The use of 11-C-5-HTP as radioactive-labeled serotonin precursor has resulted in a tumor detection rate as high as $100 \%$ (15).

\section{Endoscopic evaluation}

Endoscopic ultrasonography (EUS) as compared to conventional ultrasound is more sensitive for detection of gastric and duodenal carcinoid tumors (15).

If radiography confirms the site of carcinoid tumor, then bronchoscopy and upper/lower GI endoscopy can be done for biopsy and histopathology (5).

For diagnosis of carcinoid heart disease, 12 lead ECG and chest X-ray have a limited diagnostic value, they are sensitive in around $50 \%$ of the cases. Urinary excretion of 5-HIAA in a 24-hour period and transthoracic echocardiography are two important investigations for the diagnosis of carcinoid heart disease (7).

\section{MANAGEMENT}

arcinoid tumors have a complex treatment that depends upon the location of the pri- mary tumor and symptoms, requiring a multidisciplinary approach that involves resection of primary tumor and debulking, embolisation of liver carcinoids, somatostatin analogues and chemotherapy (1).

\section{Lung carcinoid tumors}

If patients have adequate pulmonary reserves, then surgical resection is the primary treatment of choice. Patients with less than $2 \mathrm{~cm}$ tumors in peripheral lung parenchyma have shown an excellent long term survival and low recurrence with wedge/segmental resection (16-19). Patients with large tumors require lobectomy or pneumonectomy (16).

\section{GIT carcinoid tumors}

Many of type I gastric carcinoids are detected incidentally on upper Gl endoscopy (20). They can be removed endoscopically or watchful waiting can be employed to observe symptoms or progression $(16,21)$. For gastric carcinoids II and III ( $>2 \mathrm{~cm}$ in size), gastrectomy is advised in view of poor prognosis and aggressive nature of disease $(1,8,21)$.

For midgut carcinoids en block, resection of primary tumor along with mesenteric and lymph node dissection is the goal of surgery (22). Small intestine carcinoids have severe desmoplastic reaction and infiltrative lymph nodes around vessels, making complete surgical resection difficult (12).

In appendiceal carcinoid tumors, tumor size is the best prognostic predictor (16). Tumors $<1 \mathrm{~cm}$ in size require simple appendectomy (1). For tumors $>2 \mathrm{~cm}$ in size, right hemicolectomy is the appropriate treatment because most of the time they are associated with nodal and distant metastasis (23-25).

Carcinoid tumors of the colon have a high tendency to develop distant metastasis to the liver and lymph nodes, so right hemicolectomy with mesenteric and lymph nodes dissection is advised for better prognosis $(1,26)$.

Patients with unresectable tumor or wide metastasis are candidates for debulking or cytoreductive surgeries as it can control symptoms and improve chances of survival (1). As these patients will require somatostatin analogue therapy during the course of treatment, elective cholecystectomy should be done to prevent formation of biliary sludge and stones (12). 


\section{Liver secondaries}

Patients with large metastasis in the liver can be offered percutaneous hepatic transarterial embolization with radiolabeled Yittrium $90(\mathrm{Y})$ resin or glass microspheres or radiofrequency ablation (RFA) (5).

\section{Somatostatin analogues}

Somatostatin analogues - octreotide and lanreotide - have an important role in managing symptoms of carcinoid tumors as they bind somatostatin receptors SSTR-2 and SSTR -5 and ameliorate diarrhoea and flushing in upto $80 \%$ of patients (12). Some patients have shown partial tumor regression after receiving somatostatin analogues $(27,28)$

\section{Interferon therapy}

Interferon-alpha has shown promising effect by inhibiting disease progression and suppression of symptoms like diarrhoea and flushing (29). Interferon inhibits hormone and protein synthesis from tumor cells along with inhibiting angiogenesis and boosting immunity (30). Interferon- $\alpha$ also acts synergistically with somatostatin analogues by upregulating somatostatin receptors (30).

\section{Chemotherapy}

Cytotoxic agents, including streptozocin, 5-FU and doxorubicin, have shown good results in rapidly growing carcinoid tumors such as malignant pancreatic tumors, with combination therapy having better results than single agent treatment $(1,30)$.

\section{Target therapy}

Molecular target therapies targeting vascular endothelial growth factor (VEGF), platelet-derived growth factor receptor, and mammalian target of rapamycin (mTOR) are being developed (15). vascular endothelial growth factor is among the most important regulatory factors as it has effects on angiogenesis, microvascular permeability and endothelial cell proliferation. Sunitinib, a tyrosine kinase inhibitor, has shown a promising effect on cell proliferation and angiogenesis (31). Bevacizumab, a monoclonal antibody directed against VEGF ligand, has shown a higher response rate and slower disease progression (31).

\section{ONGOING MOLECULAR TARGET STUDIES}

There are various ongoing drug clinical studies which are occurring in different phases. Ibrutinib acts by inhibiting Bruton's tyrosine kinase thereby stopping B-cell receptor signalling. Another drug explored in an ongoing trial, Fosbretabulin tromethamine, disrupts tumor blood supply by destabilising microtubules. Nivolumab inhibits immune responses through PD-1 pathways. Ipilimumab acts by binding to CTLA- 4 and blocking normal inhibitory signals allowing CTLs to destroy cancer cells. Nintedanib inhibits growth factors by inhibiting tyrosine kinase (32).

\section{CONCLUSION}

Carcinoid tumors though are rare and slow growing tumors but they can practically involve almost all organs of the body. A high index of suspicion, knowledge regarding presentation and symptoms can go long way in early detection and optimum treatment as early diagnosed carcinoid tumors have a better outcome in terms of morbidity and mortality. Molecular target therapies have shown promising effects and hold the keys for future treatment modalities.

Conflicts of interest: none declared.

Financial support: none declared.

\section{R EFERENCES}

1. Pinchot SN, Holen K, Sippel RS, Chen H. Carcinoid tumors. Oncologist 2008;13:1255-269.

2. Limaiem F, Tariq MA, Wallen JM. Lung Carcinoid Tumors. (Updated 2020
Oct 16). In: StatPearls (Internet).

Treasure Island (FL).

3. Baxi AJ, Chintapalli K, Katkar A, et al. Multimodality imaging findings in carcinoid tumors: a head to toe spectrum.
Radiographics 2017;37:516-536.

4. Pasieka JL, Longman RS, Chambers AJ, et al. Cognitive impairment associated with carcinoid syndrome. Ann Surg 2014;259:355-359. 
5. Pandit S, Annamaraju P, Bhusal K. Carcinoid Syndrome. (Updated 2020 Dec 14). In: StatPearls (Internet). Treasure Island (FL): StatPearls Publishing; 2020 Jan. Available from: https://www.ncbi.nlm.nih.gov/books/ NBK448096/.

6. Vinik A, Hughes MS, Feliberti E, et al. Carcinoid Tumors. (Updated 2018 Feb 5). In: Feingold KR, Anawalt B, Boyce A, et al, editors. Endotext (Internet). South Dartmouth (MA): MDText.com, Inc., 2000. Available from: https://www.ncbi.nlm.nih.gov/books/ NBK279162/.

7. Fox DJ, Khattar RS. Carcinoid heart disease: presentation, diagnosis, and management. Heart 2004;9:1224-1228.

8. Sippel RS, Chen H. Carcinoid Tumors. Surg Oncol Clin N Am 2006;15:463-478.

9. Feldman JM, O'Dorisio TM. Role of neuropeptides and serotonin in the diagnosis of carcinoid tumors. Am J Med 1986;81:41-48.

10. Robertson RG, Geiger WJ, Davis NB. Carcinoid tumors. Am Fam Physician 2006;74:429-434.

11. Eriksson B, Oberg K, Stridsberg M. Tumor markers in neuroendocrine tumors. Digestion 2000;62:33-38.

12. Cingam SR, Kashyap S, Karanchi H. Carcinoid Tumors. (Updated 2020 Jul 18). In: StatPearls (Internet). Treasure Island (FL): StatPearls Publishing; 2020 Jan.

13. Ganim RB, Norton JA. Recent advances in carcinoid pathogenesis, diagnosis and management. Surg Oncol 2000;9:179-179.

14. Taal BG, Hoefnagel CA, Valdes Olmos RA, et al. Combined diagnostic imaging with 131I-metaiodobenzylguanidine and 111in-pentetreotide in carcinoid tumours. Eur J Can 1996;32A:1924-1932.

15. PDQ Adult Treatment Editorial Board. Gastrointestinal Carcinoid Tumors Treatment (Adult) $(\mathrm{PDQ} \circledast)$ : Health Professional Version. 2020 Sep 16. In: $P D Q$ Cancer Information Summaries (Internet). Bethesda (MD): National Cancer Institute (US); 2002, https://www.ncbi.nlm.nih.gov/books/ NBK65791/.

16. Kulke M, Mayer R. Carcinoid tumors. N Engl J Med 1999;340:858-868.

17. Okike N, Bernatz PE, Woolner LB. Carcinoid tumors of the lung. Ann Thorac Oncol 1976;22:270-277.

18. Chughtai TS, Morin JE, Sheiner NM, et al. Bronchial carcinoid-twenty years' experience defines a selective surgical approach. Surgery 1997;122:801-808.

19. Ferguson MK, Landreneau RJ Hazelrigg SR, et al. Long-term outcome after resection for bronchial carcinoid tumors. Eur J Cardiothorac Surg 2000;18:156-161.

20. Borch $K$, Ahrén B, Ahlman $H$, et al. Gastric carcinoids: biologic behavior and prognosis after differentiated treatment in relation to type. Ann Surg 2005;242:64-73.

21. Ahlman H. Surgical treatment of carcinoid tumors of the stomach and small intestine. Ital J Gastroenterol Hepat 1999;31 Suppl 2:S198-S201.

22. Lal A, Chen H. Treatment of advanced carcinoid tumors. Curr Opin Oncol 2006;18:9-15.

23. Moertel CG, Weiland LH, Nagorney DM, et al. Carcinoid tumor of the appendix: treatment and prognosis. N Engl J Med 1987;317:1699-1701.

24. Fornaro R, Frascio M, Sticchi C, et al. Appendectomy or right hemicolectomy in the treatment of appendiceal carcinoid tumors? Tumori 2007;93:587-590.

25. McGory ML, Maggard MA, Kang H, et al. Malignancies of the appendix: Beyond case series reports. Dis Colon Rectum 2005;48:2264-2271.

26. Shebani KO, Souba WW, Finkelstein DM, et al. Prognosis and survival in patients with gastrointestinal tract tumors. Ann Surg 1999;229:815-821.

27. Kulke MH. Neuroendocrine tumours: clinical presentation and management of localized disease.

Cancer Treat Rev 2003;29:363-370.

28. Delle Fave G, Capurso G, Milione M, et al. Endocrine tumours of the stomach. Best Pract Res Clin Gastroenterol 2005;19:659-673.

29. Modlin IM, Latich I, Kidd M, et al. Therapeutic options for gastrointestinal carcinoids. Clin Gastroenterol Hepatol 2006;4:526-547.

30. Maroun J, Kocha W, Kvols L, et al. Guidelines for the diagnosis and management of carcinoid tumours. Part 1: The Gastrointestinal tract. A statement from a Canadian National Carcinoid Expert Group. Curr Oncol 2006;13:67-76.

31. Capdevila J, et al. Tumores neuroendocrinos: la era de las terapias dirigidas. Endocrinol Nutr 2012;59:438-451.

32. Vusqa UT, Patel S, Rashid MU, et al. Carcinoid Tumor: Advances in Treatment Options. Cureus 2020;12:e6641. 